ПЛАНИРОВАНИЕ И ПРОЕКТИРОВАНИЕ УСТОЙЧИВОЙ ГОРОДСКОЙ e-mail: kravhome@mail.ru МОБИЛЬНОСТИ

\title{
Lebedeva O.A. PLANNING AND DESIGN OF SUSTAINABLE URBAN MOBILITY
}

\begin{abstract}
Аннотация. Рассмотрено понятие устойчивой городской мобильности. Проведен анализ компонентов городской логистики. Выделены направления, влияющие на изменение спроса на грузопотоки в городской среде.

Ключевые слова: городская логистика, грузовые перевозки, проектирование, транспортная инфраструктура.

Abstract. The concept of sustainable urban mobility is considered. The analysis of urban logistics components has been carried out. The directions influencing the change in demand for freight traffic in the urban environment are highlighted.

Keywords: urban logistics, freight transport, design, transport infrastructure.
\end{abstract}

Планирование и проектирование мобильности является актуальным и тесно связано с повышением качества функционирования городской транспортной системы. Организация грузового движения касается широкого спектра деятельности и способности обеспечить адекватный уровень обслуживания для различных городских поставок. Городская среда исторически всегда была одним из основных производителей и потребителей товаров, поэтому большая часть перегрузочных операций производится в непосредственной близости от складов, хабов, терминалов, распределительных центров находящихся в ее пределах. С этой особенностью связаны ограничения на: количество перевозимых грузов, численность подвижного состава, которую способна выдержать улично-дорожная сеть без возникновения транспортных заторов. На грузовое движение приходится - от 10 до 15\% транспортных средств от общего потока движения [1].

Есть три основных составляющих городской логистики: варианты перемещения грузов; транспортная инфраструктура, поддерживающая стабильную работу грузового движения; операции, сопровождающие этот процесс (рисунок 1). Каждый компонент имеет подкомпоненты со своими характеристиками и ограничениями. Например, грузовые терминалы, дороги и распределительные центры являются инфраструктурными подкомпонентами городской логистики. То же самое относится к планированию, маршрутизации, парковке и погрузке / разгрузке, которые являются операциями. Грузовые перевозки сталкиваются в основном с ограничениями связанными с транспортными заторами и охраной окружающей среды. Развитие производственного сектора, появление интермодальных терминалов, а также повышение уровня жизни населения влияет на 
изменение спроса на грузовое движение в городах, и характеризуется более высокой частотой грузовых отправлений, прибывающих через городские районы [2].

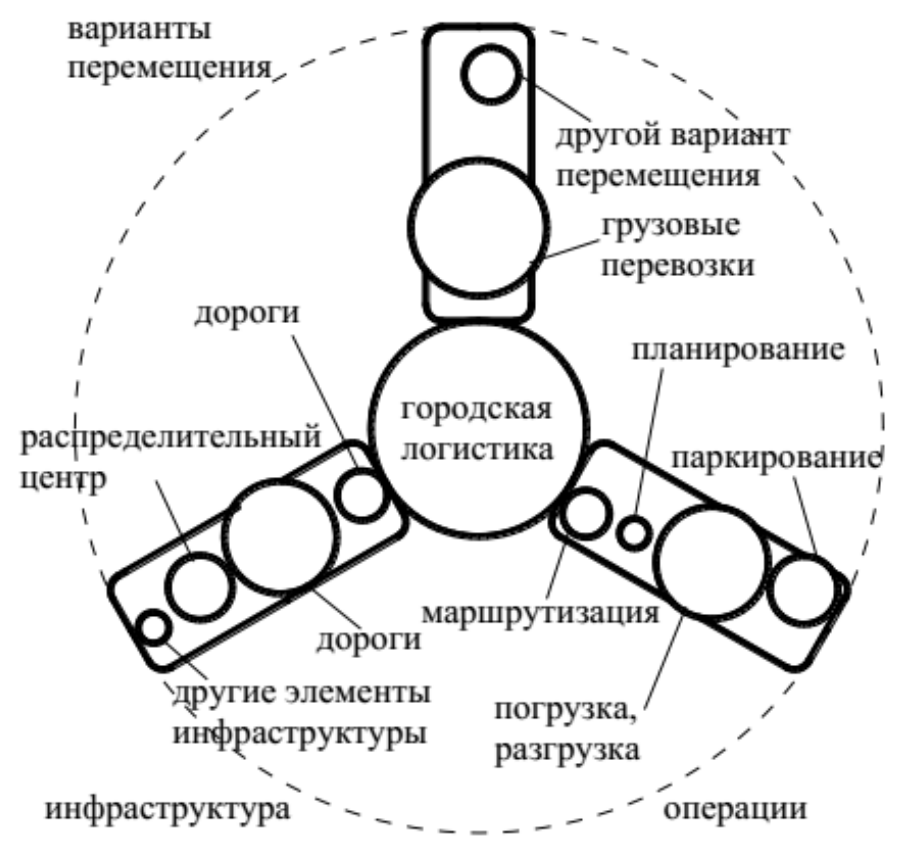

Рисунок 1 - Городская логистика и ее составляющие

В процессе транспортного планирования отмечаются сложности управления при попытке решить вопросы городской мобильности. Для решения этих задач крайне важно, чтобы все участники - поставщики, перевозчики, потребители - были заинтересованы в развитии системы городской мобильности. Это особенно актуально в развивающихся странах, где численность населения (и количество автотранспортных средств) растет, и инвестиции в городскую инфраструктуру не всегда соответствуют требуемому уровню. Масштаб, интенсивность и сложность городского грузового транспорта необходимо учитывать при планировании и разработке путей повышения эффективности городских грузовых перевозок, устранении экологических и социальных последствий.

\section{ЛИТЕРАТУРА}

1. Planning and design for sustainable urban mobility: global report on human settlements 2013 / United Nations Human Settlements Programme. P. 56-72.

2. Крипак М.Н., Лебедева О.А. Оценка состояния улично-дорожной сети крупного города // Современные технологии. Системный анализ. Моделирование. 2016. № 3(51). С. 171-174. 